\title{
Efektivitas Penggunaan Prewarming dan Water Warming untuk Mengurangi Penurunan Suhu Intraoperatif pada Operasi Ortopedi Ekstremitas Bawah dengan Anestesi Spinal
}

\author{
Emvina Husni Syam, ${ }^{1}$ Erwin Pradian, ${ }^{2}$ Eri Surahman ${ }^{2}$ \\ ${ }^{1}$ Rumah Sakit Gandaria Kebayoran Baru Jakarta Selatan, ${ }^{2}$ Departemen Anestesiologi dan Terapi \\ Intensif Fakultas Kedokteran Universitas Padjadjaran Rumah Sakit Dr. Hasan Sadikin Bandung
}

\begin{abstract}
Abstrak
Laju penurunan suhu inti tubuh dapat dikurangi dengan tindakan pemanasan sebelum operasi (prewarming) selama 30 menit dan menggunakan alas penghangat water warming selama operasi. Tujuan penelitian ini untuk mengetahui efektivitas prewarming dan alas penghangat water warming dalam mengurangi penurunan suhu intraoperatif. Penelitian dilakukan dengan metode acak terkontrol buta tunggal terhadap 30 pasien di ruang operasi bedah sentral Rumah Sakit Dr. Hasan Sadikin Bandung pada Mei-Juli 2013 yang dikelompokkan menjadi tiga, yaitu kelompok yang dilakukan prewarming selama 30 menit dan menggunakan alas penghangat water warming selama operasi, kelompok pasien yang menggunakan alas penghangat water warming selama operasi, dan kelompok kontrol. Pencatatan suhu inti tubuh dilakukan pada membran timpani tiap 15 menit sejak awal induksi sampai operasi selesai. Analisis data hasil penelitian dilakukan dengan uji statistik yaitu uji chi-kuadrat, uji-t, Uji Friedman dan uji analysis of variance (ANOVA) dengan nilai $\mathrm{p}<0,05$ dianggap bermakna. Suhu inti tubuh rata-rata pada kelompok prewarming dan water warming $36,62{ }^{\circ} \mathrm{C}(\mathrm{p}=0,023)$, kelompok water warming $36,24{ }^{\circ} \mathrm{C}(\mathrm{p}<0,001)$, dan kelompok kontrol $35,94{ }^{\circ} \mathrm{C}$ $(\mathrm{p}<0,001)$ yang secara statistik berbeda signifikan. Simpulan penelitian ini adalah penggunaan prewarming dan water warming dapat mengurangi dan memperlambat derajat penurunan suhu selama operasi.
\end{abstract}

Kata kunci: Prewarming, suhu inti tubuh, water warming

\section{Effectiveness of Prewarming and Water Warming to Reduce Intraoperative Temperature Decrease on Spinal Anesthesia for Lower Extremity Orthopedic Surgery}

\begin{abstract}
The decline rate of core body temperature can be reduced by perioperative care such as prewarming (the application of heat to patient's body prior to surgery) for 30 minutes and by using a water warming pad during surgery. The purpose of this study was to determine the effectiveness of prewarming and water warming pad to reduce intraoperative temperature decrease on spinal anesthesia. This study was conducted by a single-blind randomized controlled trials method involving 30 patients in central operating theatre Dr. Hasan Sadikin Hospital-Bandung within May-July 2013 were classified into three groups, the group of prewarming patients performed for 30 minutes and were using water warming pad during surgery; the group of patients without prewarming and were using water warming pad during surgery; and the control group. Core body temperature on tympanic membrane was recorded every 15 minutes from the initial induction through the end of operation. The result data were analyzed by using chi-square $(\chi 2)$ test, $t$ test, Friedman Test and ANOVA test, in which the value of $\mathrm{p}<0.05$ was considered significant. Average core body temperature of the prewarming and water warming pad group was $36.62^{\circ} \mathrm{C}(\mathrm{p}=0.023)$, the water warming pad group was $36.24{ }^{\circ} \mathrm{C}(\mathrm{p}<0.001)$, and the control group was $35.94{ }^{\circ} \mathrm{C}(\mathrm{p}<0.001)$, this result statistically significant. The conclusion of this study is prewarming prior to surgery and the use of water warming pad during surgery could reduce temperature decline rate during operation.
\end{abstract}

Key words: Core body temperature, prewarming, water warming

Korespondensi: Emvina Husni Syam, dr., SpAn, RS. Gandaria, Jl. Gandaria Tengah II No. 6-14, Kebayoran Baru, Jakarta Selatan, mobile 081317278292, email emvinahs@yahoo.com 


\section{Pendahuluan}

Hipotermia merupakan salah satu komplikasi yang paling sering terjadi pada pembedahan. Penelitian menunjukkan sekitar $70 \%$ pasien pascapembedahan akan mengalami keadaan hipotermia. ${ }^{1}$ Pada penelitian yang dilakukan terhadap 108 pasien yang menjalani operasi elektif dan emergensi nonkardiak, didapatkan $57,8 \%$ pasien mengalami hipotermia ketika tiba di ICU. ${ }^{2}$

Hipotermia didefinisikan sebagai keadaan suhu inti tubuh berada di bawah $35{ }^{\circ} \mathrm{C}$ dan merupakan faktor risiko independen terhadap mortalitas setelah trauma. ${ }^{3}$ Bila suhu kurang dari $36{ }^{\circ} \mathrm{C}$ dipergunakan sebagai patokan suhu hipotermia, maka insidensi hipotermia sekitar $50-70 \%$ dari seluruh pasien yang menjalani pembedahan. ${ }^{4}$

Anestesi spinal merupakan teknik anestesi yang sering kali dijadikan pilihan pada operasi ortopedi ekstremitas bawah. Anestesi spinal menyebabkan penurunan suhu tubuh melalui 3 (tiga) mekanisme, yaitu terjadi redistribusi panas dari pusat ke perifer akibat vasodilatasi blok saraf simpatis, hilangnya termoregulasi yang ditandai penurunan ambang menggigil, dan peningkatan kehilangan panas oleh efek vasodilatasi. ${ }^{5}$

Pencegahan hipotermia dapat kita lakukan secara pasif dengan menutupi tubuh memakai selimut atau kain bedah dan pengaturan suhu ruangan. Suhu di ruangan operasi seharusnya tetap dijaga sekitar $20-24{ }^{\circ} \mathrm{C}$ yang bertujuan meminimalkan pertumbuhan bakteri. Untuk menjaga agar suhu inti pasien berada pada 36 ${ }^{0} \mathrm{C}$, maka suhu ruangan operasi harus dijaga pada suhu $21-24{ }^{\circ} \mathrm{C}$. Pencegahan secara aktif dapat dilakukan dengan penghangatan cairan infus serta menggunakan alas penghangat. ${ }^{1}$

Manajemen suhu inti tubuh yang adekuat dapat kita lakukan dengan cara pengukuran suhu pada saat preoperatif dan intraoperatif. Tindakan pemanasan tubuh sebelum operasi (prewarming) akan meningkatkan kadar panas jaringan perifer sehingga akan menurunkan redistribusi panas dari inti tubuh ke jaringan perifer setelah induksi anestesi.

Penelitian sebelum ini menggunakan alas penghangat forced airwarming dan electric heating pad pada prosedur operasi ortopedi total knee replacement dengan teknik anestesi kombinasi spinal-epidural ternyata mencegah hipotermia dengan menjaga suhu antara 36,8$36,9^{\circ} \mathrm{C}$. Penelitian lain yang menggunakan alas penghangat forced air warming dengan standar hospital blankets yang diatur pada suhu $38{ }^{\circ} \mathrm{C}$ serta commercial blankets dengan dipanaskan pada suhu $43{ }^{\circ} \mathrm{C}$ mampu menjaga suhu lebih dari $36^{\circ} \mathrm{C}$ pada saat akhir proses pembedahan. Forced air warming sering juga terbukti tidak mampu menjaga kondisi normotermia pada transplantasi hati, multitrauma, operasi bedah toraks, serta operasi coronary artery bypass grafting (CABG). ${ }^{6-9}$

Air adalah media yang lebih efisien untuk perpindahan panas per unit luas permukaan tubuh bila dibandingkan dengan media udara. Penggunaan alat water warming ternyata dapat mempertahankan normotermia intraoperatif pada operasi transplantasi hati, bahkan suhu inti meningkat lebih tinggi bila dibandingkan dengan forced air warming yang diletakkan di atas dan bawah pasien. ${ }^{8-10}$ Tujuan penelitian ini adalah mengetahui efektivitas prewarming serta alas penghangat water warming untuk mengurangi penurunan suhu intraoperatif

\section{Subjek dan Metode}

Penelitian ini merupakan penelitian kuantitatif intervensi dengan menggunakan rancangan uji klinis acak terkontrol buta tunggal (single blind randomized controlled trial). Cara pengambilan sampel dilakukan dengan teknik consecutive sampling dengan alokasi subjek ke dalam suatu kelompok dilakukan dengan cara random blok permutasi. Subjek penelitian ini adalah pasien yang menjalani operasi ortopedi ekstremitas bawah di ruang operasi bedah sentral Rumah Sakit Dr. Hasan Sadikin Bandung pada Mei-Juli 2013 dengan mempergunakan anestesi spinal yang sebelumnya telah diberikan penjelasan mengenai penelitian ini dan telah menyatakan kesediaan untuk partisipasi dalam penelitian (informed consent) serta memenuhi kriteria inklusi penelitian, yaitu status fisik ASA I-II, usia 18-45 tahun, indeks massa tubuh/body 
mass index (BMI) 18,5-25. Kriteria eksklusi, yaitu suhu tubuh $\leq 35,5^{\circ} \mathrm{C}$ atau $\geq 38{ }^{\circ} \mathrm{C}$, sedang mendapat terapi antipiretik, dan masih berada dalam durasi kerja obat. Pengeluaran sampel apabila terjadi kegagalan anestesi regional spinal sehingga dilakukan perubahan teknik anestesi menjadi anestesi umum.

Randomisasi sampel dengan menggunakan tabel bilangan random, lalu dibagi menjadi 3 (tiga) kelompok. Sebelum tindakan, diberikan cairan Ringer laktat (RL) $10 \mathrm{~mL} / \mathrm{kgBB}$ dalam waktu 20 menit dengan suhu cairan $37{ }^{\circ} \mathrm{C}$. Suhu pasien diukur pada daerah membran timpani mempergunakan alat termometer inframerah dan dilakukan pencatatan data tekanan darah sistol-diastol, nadi, dan laju napas.

Suhu kamar operasi diatur pada suhu $21^{\circ} \mathrm{C}$, kemudian dilakukan pemasangan alat pantau tekanan darah noninvasif, elektrokardiografi, serta pulse oksimetri. Pada meja operasi untuk kelompok prewarming dan juga water warming dilengkapi blanketrol III yang suhunya diatur $38{ }^{\circ} \mathrm{C}$. Pasien dibaringkan di atas meja selama 30 menit, kemudian suhu inti diukur kembali. Meja operasi pada kelompok water warming dilengkapi blanketrol III yang suhunya diatur pada $38{ }^{\circ} \mathrm{C}$, kemudian dilakukan pengukuran suhu. Pengukuran suhu juga dilakukan pada kelompok yang tidak mempergunakan water warming.

Tindakan anestesi spinal dilakukan pada lokasi L3-4 dengan anestetik lokal bupivakain 0,5\% 12,5 mg, disuntikkan dengan kecepatan $0,25 \mathrm{~mL} /$ detik. Setelah onset obat anestesi lokal tercapai, pasien diberikan sedasi dengan midazolam 0,05 mg/kgBB.

Hipotensi yang terjadi akibat anestesi spinal diatasi dengan pemberian efedrin dosis $5 \mathrm{mg}$ intravena dan bila terjadi bradikardia diberi sulfas atropin 0,5-1 mg intravena. Pengukuran suhu inti, tekanan darah, nadi, laju napas, dan saturasi oksigen $\left(\mathrm{SpO}_{2}\right)$ dilakukan pada menit ke-5, 15, 30, 45, 60, 75, 90, 105, 120, dan 150 setelah anestesi spinal selesai dilakukan.

Analisis data memakai analysis of variance (ANOVA) untuk membandingkan perbedaan suhu inti rata-rata ketiga kelompok perlakuan apabila data dengan distribusi normal atau Uji Kruskal-Wallis jika data tidak dengan distribusi normal. Apabila variabel perancu mempunyai nilai bermakna, maka analisis akan dilakukan menggunakan analisis kovarian. Kemaknaan hasil uji ditentukan berdasarkan nilai p<0,05.

\section{Hasil}

Hasil analisis statistik menunjukkan bahwa untuk semua karakteristik, yaitu jenis kelamin,

Tabel 1 Nilai dan Simpang Baku Rata-rata Karakteristik Umum Subjek Penelitian pada Tiap-tiap Kelompok

\begin{tabular}{|c|c|c|c|c|c|c|c|}
\hline & \multicolumn{6}{|c|}{ Kelompok } & \multirow{3}{*}{$\underset{p}{\text { Nilai }}$} \\
\hline & \multicolumn{2}{|c|}{$\begin{array}{c}\text { Prewarming } \\
+ \text { Water Warming } \\
\end{array}$} & \multicolumn{2}{|c|}{ Water Warming } & \multicolumn{2}{|r|}{ Kontrol } & \\
\hline & $\mathbf{n}$ & Rata-rata (SD) & $\mathbf{n}$ & Rata-rata (SD) & $\mathbf{n}$ & Rata-rata (SD) & \\
\hline Jenis kelamin & & & & & & & 0,523 \\
\hline Laki-laki & 9 & 37,5 & 8 & 33,3 & 7 & 29,2 & \\
\hline Perempuan & 1 & 10,0 & 2 & 20,0 & 3 & 50,0 & \\
\hline Usia (tahun) & 30,30 & 6,76 & 27,40 & 7,66 & 28,50 & 8,99 & 0,710 \\
\hline BMI & 21,72 & 1,37 & 21,83 & 1,57 & 22,08 & 1,17 & 0,838 \\
\hline Lama anestesi & 126,00 & 21,44 & 130,50 & 24,54 & 129,00 & 21,44 & 0,902 \\
\hline
\end{tabular}

Keterangan: Bermakna $(\mathrm{p}<0,05)$. Nilai p dihitung berdasarkan uji ANOVA, kecuali jenis kelamin dengan uji chi-kuadrat. SD: simpangan baku 
Tabel 2 Nilai dan Simpang Baku Rata-rata Karakteristik Selama Pembedahan pada Tiaptiap Kelompok

\begin{tabular}{lccccccc}
\hline & \multicolumn{9}{c}{ Kelompok } & \\
\cline { 2 - 6 } & \multicolumn{2}{c}{$\begin{array}{c}\text { Prewarming } \\
+ \text { Water Warming }\end{array}$} & \multicolumn{2}{c}{ Water Warming } & \multicolumn{2}{c}{ Kontrol } & \multirow{2}{*}{ Nilai p } \\
\cline { 2 - 6 } & Rata-rata & SB & Rata-rata & SB & Rata-rata & SB & \\
\hline $\begin{array}{l}\text { Jumlah cairan } \\
\text { masuk }\end{array}$ & $1.575,00$ & 213,76 & $1.560,00$ & 233,09 & $1.545,00$ & 153,56 & 0,947 \\
$\begin{array}{l}\text { Jumlah cairan } \\
\text { keluar }\end{array}$ & 381,50 & 227,07 & 330,00 & 186,63 & 310,00 & 98,74 & 0,658 \\
$\begin{array}{l}\text { Jumlah } \\
\text { perdarahan }\end{array}$ & 275,00 & 221,42 & 225,00 & 175,19 & 207,50 & 86,64 & 0,660 \\
\hline
\end{tabular}

Keterangan: Bermakna $(\mathrm{p}<0,05)$. Nilai p dihitung berdasarkan uji ANOVA. SB: simpangan baku

usia, BMI, lama anestesi, jumlah cairan masuk, jumlah cairan keluar, jumlah perdarahan, dan suhu kamar operasi pada ketiga kelompok perlakuan tidak berbeda bermakna $(p>0,05)$. Hal ini membuktikan bahwa subjek penelitian mempunyai karakteristik homogen dan layak diperbandingkan (Tabel 1).

Suhu inti rata-rata ketiga kelompok perlakuan terlihat menurun selama anestesi. Suhu awal rata-rata (suhu pada 5 menit setelah dilakukan anestesi spinal) pada kelompok prewarming + water warming selama operasi adalah $37,12^{\circ} \mathrm{C}$. Penurunan suhu terlihat mulai pada menit ke15 menit setelah anestesi spinal berlangsung sampai menit ke-150. Suhu inti rata-rata pada menit ke-150 adalah $36,33{ }^{\circ} \mathrm{C}$ merupakan suhu terendah kelompok prewarming dan water warming selama operasi.

Hasil pengukuran awal dari suhu rata-rata (5 menit setelah tindakan anestesi spinal) pada kelompok water warming berada pada suhu $37,05^{\circ} \mathrm{C}$. Penurunan suhu pada kelompok water warming mulai terlihat sejak menit ke15 pascaanestesi spinal berlangsung hingga menit ke-120, setelah itu suhu menjadi relatif konstan. Suhu terendah rata-rata pada menit ke-120 adalah $35,9{ }^{\circ} \mathrm{C}$ dan merupakan suhu terendah pada kelompok water warming.

Suhu tubuh awal rata-rata $(5$ menit setelah anestesi spinal) terhadap kelompok kontrol pada suhu $37,04{ }^{\circ} \mathrm{C}$. Penurunan suhu kelompok kontrol terlihat saat menit ke-15 pascaanestesi

Tabel 3 Nilai dan Simpang Baku Rata-rata Suhu Ruangan pada Tiap-tiap Kelompok

\begin{tabular}{lccccccc}
\hline \multirow{2}{*}{ Suhu Tubuh } & \multicolumn{6}{c}{ Kelompok } & \\
\cline { 2 - 6 } & \multicolumn{2}{c}{$\begin{array}{c}\text { Prewarming } \\
\text { +Water Warming }\end{array}$} & \multicolumn{2}{c}{ Water Warming } & \multicolumn{2}{c}{ Kontrol } & \multirow{2}{*}{ Nilai p } \\
\cline { 2 - 6 } & Rata-rata & SB & Rata-rata & SB & Rata-rata & SB & \\
\hline & & & & & & & \\
T-0 & 21,00 & 0,00 & 21,00 & 0,00 & 21,00 & 0,00 & 1,000 \\
T-30 & 21,60 & 1,25 & 21,90 & 1,28 & 21,50 & 1,41 & 0,875 \\
T-60 & 21,70 & 1,25 & 21,50 & 1,26 & 21,70 & 0,82 & 0,209 \\
T-90 & 21,60 & 0,94 & 21,80 & 1,31 & 21,90 & 1,19 & 0,185 \\
T-120 & 21,50 & 0,67 & 21,40 & 1,33 & 21,60 & 1,07 & 0,686 \\
T-150 & 21,70 & 1,05 & 21,90 & 1,19 & 21,80 & 0,84 & 0,566 \\
\hline
\end{tabular}

Keterangan: Bermakna $(\mathrm{p}<0,05)$. Nilai p dihitung berdasarkan uji ANOVA. SB: simpangan baku 
Tabel 4 Nilai dan Simpang Baku Rata-rata Suhu Inti pada Tiap-tiap Kelompok

\begin{tabular}{|c|c|c|c|c|c|c|c|}
\hline \multirow{3}{*}{ Pengamatan } & \multicolumn{6}{|c|}{ Penurunan Suhu Intraoperatif } & \multirow{3}{*}{ Nilai p } \\
\hline & \multicolumn{2}{|c|}{ Prewarming + Water Warming } & \multicolumn{2}{|c|}{ Water Warming } & \multicolumn{2}{|c|}{ Kontrol } & \\
\hline & Rata-rata & SB & Rata-rata & SB & Rata-rata & SB & \\
\hline $\mathrm{T}-0$ & 37,10 & 0,11 & 37,07 & 0,12 & 37,04 & 0,10 & 0,503 \\
\hline $\mathrm{T}-5$ & 37,12 & 0,16 & 37,05 & 0,14 & 37,04 & 0,11 & 0,479 \\
\hline $\mathrm{T}-15$ & 36,79 & 0,23 & 36,57 & 0,13 & 36,20 & 0,21 & 0,058 \\
\hline $\mathrm{T}-30$ & 36,67 & 0,22 & 36,37 & 0,17 & 35,70 & 0,15 & $<0,001$ \\
\hline $\mathrm{T}-45$ & 36,65 & 0,17 & 36,25 & 0,21 & 35,60 & 0,16 & $<0,001$ \\
\hline T-60 & 36,60 & 0,14 & 36,02 & 0,19 & 35,60 & 0,11 & $<0,001$ \\
\hline $\mathrm{T}-75$ & 36,58 & 0,27 & 36,00 & 0,28 & 35,60 & 0,09 & $<0,001$ \\
\hline T-90 & 36,50 & 0,29 & 35,92 & 0,29 & 35,61 & 0,11 & $<0,001$ \\
\hline T-105 & 36,45 & 0,11 & 35,91 & 0,33 & 35,65 & 0,18 & $<0,001$ \\
\hline $\mathrm{T}-120$ & 36,42 & 0,07 & 35,90 & 0,32 & 35,66 & 0,24 & $<0,001$ \\
\hline $\mathrm{T}-135$ & 36,36 & 0,05 & 35,92 & 0,29 & 35,66 & 0,30 & 0,002 \\
\hline $\mathrm{T}-150$ & 36,33 & 0,30 & 35,92 & 0,33 & 35,66 & 0,17 & 0,048 \\
\hline Rata-rata & 36,62 & 0,17 & 36,24 & 0,23 & 35,94 & 0,16 & \\
\hline Nilai p*) & \multicolumn{2}{|c|}{0,023} & \multicolumn{2}{|c|}{$<0,001$} & \multicolumn{2}{|c|}{$<0,001$} & \\
\hline Nilai p**) & \multicolumn{7}{|c|}{0,034} \\
\hline Nilai $p^{* * *}$ ) & \multicolumn{7}{|c|}{0,003} \\
\hline
\end{tabular}

Keterangan: T0: sebelum induksi, T5: 5 menit T15: 15 menit, T30: 30 menit, T45: 45 menit, T60: 60 menit, T75: 75 menit, T90: 90 menit, T105: 105 menit, T120: 120 menit, T135: 135 menit, T150: 150 menit. Nilai p dihitung berdasarkan uji ANOVA, nilai $\mathrm{p}^{*}$ ) berdasarkan Uji Friedman, nilai $\mathrm{p}^{* *}$ ) berdasarkan uji T prewarming vs water warming, nilai $\mathrm{p}^{* * *}$ ) berdasarkan uji T prewarming vs kontrol. Nilai bermakna $(\mathrm{p}<0,05)$

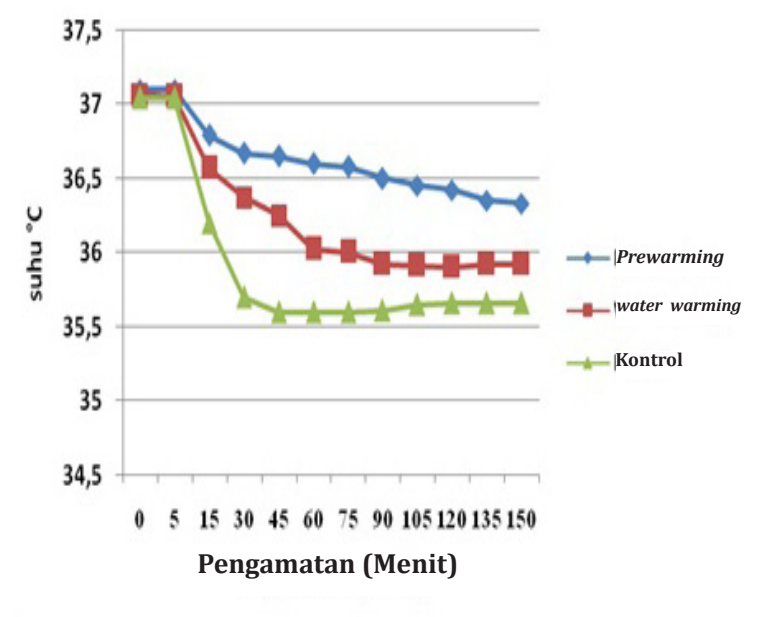

Gambar Grafik Hubungan antara Lama Anestesi dan Penurunan Suhu pada Ketiga Kelompok Penelitian spinal dan berlangsung hingga menit ke-45, setelah itu suhu tubuh akan relatif konstan. Suhu rata-rata pada menit ke-45-90 sebesar $35,6{ }^{\circ} \mathrm{C}$ yang merupakan suhu terendah pada kelompok kontrol.

Semua subjek mengalami penurunan suhu dengan derajat berbeda. Berdasarkan derajat penurunan suhu tubuh pada menit ke-30-150 pascainduksi antara ketiga kelompok memiliki perbedaan yang bermakna $(p<0,05)$. Suhu inti keseluruhan pada awal hingga akhir anestesi didapatkan perbedaan yang sangat bermakna $(\mathrm{p}<0,05)$ antara kelompok prewarming dan water warming apabila dibandingkan dengan kelompok water warming $\left(36,62{ }^{\circ} \mathrm{C}\right.$ vs 36,24 $\left.{ }^{0} \mathrm{C}\right)$. Perbedaan bermakna didapatkan antara kelompok prewarming dan water warming serta kelompok kontrol $\left(36,62{ }^{\circ} \mathrm{C}\right.$ vs $\left.35,94{ }^{\circ} \mathrm{C}\right)$. 
Tabel 5 Nilai dan Simpang Baku Rata-rata Derajat Penurunan Suhu Inti pada Tiap-tiap Kelompok

\begin{tabular}{|c|c|c|c|c|c|c|c|}
\hline \multirow{3}{*}{ Pengamatan } & \multicolumn{6}{|c|}{ Perubahan Suhu Intraoperatif } & \multirow{3}{*}{ Nilai p } \\
\hline & \multicolumn{2}{|c|}{$\begin{array}{c}\text { Prewarming } \\
+ \text { Water Warming }\end{array}$} & \multicolumn{2}{|c|}{ Water Warming } & \multicolumn{2}{|c|}{ Kontrol } & \\
\hline & Rata-rata & SB & Rata-rata & SB & Rata-rata & SB & \\
\hline Т $0-5$ & 0,00 & 0,00 & 0,02 & 0,04 & 0,00 & 0,00 & 0,125 \\
\hline Т $0-15$ & 0,31 & 0,15 & 0,50 & 0,14 & 0,84 & 0,27 & 0,113 \\
\hline Т $0-30$ & 0,43 & 0,19 & 0,70 & 0,16 & 1,34 & 0,21 & $<0,001$ \\
\hline Т $0-45$ & 0,45 & 0,14 & 0,82 & 0,17 & 1,44 & 0,22 & $<0,001$ \\
\hline Т $0-60$ & 0,50 & 0,15 & 1,05 & 0,14 & 1,44 & 0,19 & $<0,001$ \\
\hline Т $0-75$ & 0,52 & 0,29 & 1,07 & 0,24 & 1,44 & 0,18 & $<0,001$ \\
\hline Т 0-90 & 0,60 & 0,31 & 1,15 & 0,24 & 1,43 & 0,20 & $<0,001$ \\
\hline Т 0-105 & 0,63 & 0,15 & 1,18 & 0,28 & 1,38 & 0,26 & $<0,001$ \\
\hline Т 0-120 & 0,68 & 0,05 & 1,19 & 0,27 & 1,38 & 0,28 & $<0,001$ \\
\hline Т 0-135 & 0,76 & 0,05 & 1,13 & 0,27 & 1,38 & 0,39 & 0,012 \\
\hline Т $0-150$ & 0,80 & 0,30 & 1,16 & 0,29 & 1,45 & 0,44 & 0,048 \\
\hline Rata-rata T0-60 mnt & 0,34 & 0,13 & 0,62 & 0,13 & 1,01 & 0,18 & \\
\hline Nilai $p^{*}$ ) & & & $<0,001$ & & & & \\
\hline Nilai $\mathrm{p}^{* *}$ ) & & & $<0,001$ & & & & \\
\hline Rata-rata T0-150 mnt & 0,52 & 0,16 & 0,91 & 0,20 & 1,23 & 0,24 & \\
\hline Nilai $p^{*}$ ) & & & 0,049 & & & & \\
\hline Nilai p**) & & & 0,002 & & & & \\
\hline
\end{tabular}

Keterangan: T0-5: 0-5 menit postspinal,T0-15: 0-15 menit postspinal, T0-30: 0-30 menit postspinal, T0-45: 0-45 menit postspinal , T0-60: 0-60 menit postspinal, T0-75: 0-75 menit postspinal, T0-90: 0-90 menit postspinal, T0-105: 0-105 menit postspinal, T0-120: 0-120 menit postspinal , T0-135: 0-135 menit postspinal,T0-150: 0-150 menit postspinal, Nilai p dihitung berdasarkan uji ANOVA, nilai $\mathrm{p}^{*}$ ) berdasarkan uji T prewarming vs water warming, nilai $\mathrm{p}^{* *}$ ) berdasarkan uji T prewarming vs kontrol.bermakna $(\mathrm{p}<0,05)$

Perbandingan suhu tubuh antara kelompok prewarming dan water warming, kelompok water warming dan kelompokkontrol pada saat dilakukan induksi dan 15 menit pascainduksi memiliki perbedaan tidak bermakna $(\mathrm{p}>0,05)$. Mulai pada menit ke-30-150 pascainduksi didapatkan perbedaan yang sangat bermakna $(\mathrm{p}<0,05)$.

\section{Pembahasan}

Saat satu jam pertama pascainduksi terjadi redistribusi panas dari pusat tubuh ke perifer sehingga terjadi penurunan suhu inti tubuh
1-20 ${ }^{\circ} \mathrm{C}$. Penurunan suhu tubuh berlangsung lebih lambat, keadaan ini diakibatkan oleh kehilangan kalor tubuh yang lebih besar bila dibandingkan dengan daya produksinya.Subjek penelitian ini mengalami penurunan suhu inti dalam waktu 1 jam pertama, penurunan suhu rata-rata kelompok prewarming dan water warming dalam 1 jam pertama adalah $0,34{ }^{\circ} \mathrm{C}$.

Penurunan suhu tubuh rata-rata kelompok water warming adalah $0,62^{\circ} \mathrm{C}$, sedangkan pada kelompok kontrol sebesar $1,01^{\circ} \mathrm{C}$. Penurunan suhu tubuh pada kelompok prewarming dan water warming ternyata lebih lambat, suhu terendah dicapai pada menit ke-150 atau 30 
menit lebih lambat bila dibandingkan dengan kelompok water warming dan 105 menit lebih lambat bila dibandingkan dengan kelompok kontrol (menit ke-45). Penurunan suhu terjadi pada 1 jam pertama setelah anestesi spinal, hal ini selain disebabkan redistribusi panas dari pusat ke perifer karena vasodilatasi akibat blok simpatis, juga karena kehilangan kemampuan termoregulasi tubuh ditandai dengan terjadi penurunan ambang menggigil dan hilangnya vasokonstriksi termoregulasi di bawah daerah blok, simpatik sehingga terjadi peningkatan kehilangan panas dari vasodilatasinya. ${ }^{5,11}$

Besarnya penurunan suhu pada kelompok prewarming dan water warming lebih minimal apabila dibandingkan dengan kontrol. Keadaan ini karena tindakan pemanasan yang dilakukan pada saat sebelum operasi (prewarming) akan meningkatkan panas jaringan perifer sehingga menurunkan redistribusi panas dari inti tubuh ke jaringan perifer setelah induksi anestesi. ${ }^{11}$ Penurunan suhu inti kelompok water warming lebih minimal apabila dibandingkan dengan kontrol, hal tersebut disebabkan oleh proses redistribusi atau perpindahan kalor dari inti ke daerah perifer pada kelompok water warming lebih minimal karena telah menggunakan alas penghangat, tetapi pada kelompok ini tidak terjadi peningkatan kadar panas pada jaringan perifer sebelumnya. Proses redistribusi panas juga sangat bergantung pada besarnya gradien antara suhu inti dan perifer (permukaan kulit). Semakin sempit gradien antara suhu inti dan suhu perifer, maka akan semakin kecil proses redistribusi.

Penelitian ini menunjukkan bahwa dengan melakukan prewarming dan penggunaan alas penghangat water warming saat pembedahan akan memperlambat penurunan suhu tubuh. Penurunan suhu mencapai titik terendah pada kelompok prewarming dan water warming baru terjadi pada menit ke-150 atau 30 menit lebih lambat dibandingkan dengan kelompok water warming serta 105 menit lebih lambat bila dibandingkan dengan kelompok kontrol

Perpindahan panas media water warming bergantung pada specific heat, yaitu besarnya energi yang dibutuhkan untuk meningkatkan suhu $1{ }^{\circ} \mathrm{C}$ adalah $4,18 \mathrm{~J} / \mathrm{g} /{ }^{\circ} \mathrm{C}(1,0035 \mathrm{~J} / \mathrm{g} /$
${ }^{\circ} \mathrm{C}$ untuk udara). Tindakan prewarming akan meningkatan suhu jaringan perifer sebanyak 69 kkal dalam 30 menit, hal ini berguna untuk mencegah kehilangan panas akibat tindakan anestesi yang akan menyebabkan vasodilatasi sehingga 46 kkal panas akan didistribusikan selama 1 jam pertama serta ditambah $17 \mathrm{kkal}$ akibat redistribusi panas inti tubuh ke jaringan perifer dalam waktu 2 jam..$^{9,11}$

Water warming bersifat tidak memantulkan cahaya sehingga proses pelepasan panas tubuh secara radiasi tetap terjadi, sedangkan proses radiasi merupakan kontributor yang terbesar (40\%) pada proses perpindahan panas tubuh ke lingkungan.

Kehilangan 28\% kalor melalui evaporasi terjadi pada tubuh yang basah/lembab, yaitu mukosa, permukaan kulit, dan melalui paruparu. Bagian tubuh pasien yang tidak ditutupi kain pada penelitian ini yaitu wajah, tangan tempat pemasangan infus, dan probe saturasi. Pada bagian yang tidak tertutup ini proses perpindahan panas meliputi radiasi, konveksi, konduksi, dan evaporasi akan terjadi.

Konduksi merupakan proses perpindahan panas secara langsung antara 2 (dua) materi padat yang berhubungan langsung tanpa ada transfer panas molekul. Panas menjalar dari bagian yang suhunya lebih tinggi ke suhu yang lebih rendah dengan besar kalor yang hilang melalui proses ini akan bergantung pada faktor perbedaan suhu antara kulit dan benda padat yang menempel, serta sifat konduktivitas kulit yang dapat mengakibatkan proses konduksi, terutama apabila suhu benda tersebut berbeda jauh di bawah suhu permukaan kulit. Kain alas tempat tidur dan kain steril penutup pasien yang basah karena darah atau cairan irigasi dapat memperbesar derajat konduksi. Proses pelepasan panas tubuh secara konduksi pada penelitian ini masih tetap terjadi.

Konveksi adalah perambatan panas yang terjadi melalui media cair atau gas. Besarnya konveksi bergantung pada luas kontak dan perbedaan suhu media. Proses ini dipengaruhi oleh suhu pada permukaan kulit, suhu udara, luas permukaan kulit, dan kecepatan gerak udara di sekitar kulit, hilangnya panas yang dapat terjadi kira-kira $32 \% .{ }^{12-14}$ Pada 
penelitian ini hampir seluruh tubuh pasien tertutup dengan kain terkecuali wajah, tangan tempat pemasangan infus dan probe saturasi, sehingga kehilangan panas melalui konveksi dapat diminimalisasi.

\section{Simpulan}

Metode prewarming selama 30 menit sebelum operasi disertai penggunaan alas penghangat water warming selama operasi tidak menahan laju penurunan suhu inti tubuh pasien, tetapi dapat mengurangi dan memperlambat derajat penurunan suhu yang terjadi selama periode anestesi spinal.

\section{Daftar Pustaka}

1. Bellamy C. Inadvertent hypothermia in the operating theatre: an examination. J Perioperative Practice. 2007;17(1):18-25.

2. Abelha FJ, Castro MA, Neves AM, Landeiro NM, Santos CC. Hypothermia in a surgical intensive care unit. BMC Anesthesiol. 2005;7(5):1-10.

3. Inaba $K$, Teixeire PG, Rhee P, Brown $C$, Salim A, DuBose J dkk. Mortality impact of hypothermia after cavitary explorations in trauma. Word J Surg. 2009;33:864-9.

4. Frank SM, Shir Y, Raja SN, Fleisher LA, Beattie C. Core hypothermia and skin surface temperature gradients: epidural versus general anesthesia and the effects of age. Anesthesiology. 1994;80:502-8.

5. Liu SS, McDonald SB. Current issues in spinal anesthesia. Anesthesiology. 2001;94:888-906.

6. Ng V, Lai A, Ho V. Comparison of forced air warming and electric heating pad for maintenance of body temperature during total knee replacement. Anesthesia. 2006;61:1100-4.

7. Kabbara A, Goldlust SA, Smith CE, Hagen JF, Pinchak AC. Randomized prospective comparison of forced air warming using hospital blankets versus commercial blankets in surgical patients. Anesthesiology. 2002;97:338-44.

8. Wadhwa A, Komatsu R, Sungur MO, Barnes P, In J, Sessler DI, dkk. New circulating water devices warm more quickly than forced air in volunteers. Anesth Analg. 2007;105:1681-7.

9. Cooper S. The effect of perioperative warming on patiens postoperative temperatures. AORN J. 2006;83(5):107384.

10. Taguchi A, Ratnaraj J, Kabon B, Sharma $N$, Lenhardt R, Sessler DI, dkk. Effects of a circulating water garment and forced air warming on body heat content and core temperature. Anesthesiology. 2004; 100:1058-64.

11. Sessler DI, Schroeder MBA, Merrifield B. Optimal duration and temperature of prewarming. Anesthesiology. 1995; 82(3):674-81.

12. Stoelting RK, Hillier SC. Thermoregulation. Pharmacology and physiology in anesthetic practice. Edisi ke-4. Philadelphia: Lippincott Williams and Wilkins; 2006.

13. Fried DJ. Hypothermia's chilling effect on outcomes. American Association of Nurse Anestheticts J. 2004;(35):22-3.

14. Hardy JD, Du Bois EF. The technic of measuring radiation and convection. J Nutrit. 1938;15:461-7. 